\title{
Monitoramento de artigos sobre a utilização de nanocompósitos com matriz de poliuretano aplicados à engenharia de tecidos para o reparo ósseo
}

\author{
Monitoring articles on the use of nanocomposites with polyurethane matrix applied to tissue \\ engineering for bone repair
}

Artículos de seguimiento sobre el uso de nanocompuestos con matriz de poliuretano aplicados a la ingeniería tisular para la reparación ósea

\author{
Hitalo de Jesus Bezerra da Silva \\ ORCID: https://orcid.org/0000-0001-6008-3600 \\ Universidade Federal do Piauí, Brasil \\ E-mail: hitalo.ufpi@gmail.com \\ Jairo dos Santos Trindade \\ ORCID: https://orcid.org/0000-0002-3068-6985 \\ Universidade Federal do Piauí, Brasil \\ E-mail: jairotrindade170@gmail.com \\ Domingos Rodrigues da Silva Filho \\ ORCID: https://orcid.org/0000-0003-0031-4950 \\ Universidade Federal do Piauí, Brasil \\ E-mail: domingosbrownm9@gmail.com \\ Marcel Leiner de Sá \\ ORCID: https://orcid.org/0000-0001-9383-3586 \\ Universidade Federal do Piauí, Brasil \\ E-mail: marcel-pi@hotmail.com \\ Humberto Denys de Almeida Silva \\ ORCID: https://orcid.org/0000-0002-3144-7070 \\ Universidade Federal do Piauí, Brasil \\ E-mail: hdas0912@hotmail.com \\ Raiany Sena de Oliveira \\ ORCID: https://orcid.org/0000-0003-4623-8156 \\ Centro Universitário Maurício de Nassau, Brasil \\ E-mail: raianysena-oliveira@hotmail.com \\ José Milton Elias de Matos \\ ORCID: https://orcid.org/0000-0003-3476-399X \\ Universidade Federal do Piauí, Brasil \\ E-mail: jmematos@ufpi.edu.br
}

\begin{abstract}
Resumo
Nanocompósitos com matriz de poliuretano são materiais com propriedades interessantes para a Engenharia de tecidos, podendo ser usados na fabricação de arcabouço para regeneração óssea. O objetivo dessa pesquisa foi avaliar a evolução das publicações cientificas relacionadas a nanocompósitos com matriz de poliuretano aplicados à regeneração do tecido ósseo. Realizou-se buscas nas bases de periódicos Web of Science e Scopus, fazendo uso de uma combinação de palavras-chave, e os resultados reportados foram tabulados e analisados. Verificou-se que os primeiros documentos datam de 2009. A China detém o maior número de publicações, seguido pela Malásia e Vietnã. As principais áreas de pesquisa são Engenharia, Ciência dos materiais e Engenharia química. Percebeu-se uma valorização crescente da temática, com aumento na produção e impacto dessas publicações. Pode-se considerar que a questão levantada possui grande relevância por ser um campo de estudos promissor que promete trazer importantes avanços à engenharia de tecidos ósseos.
\end{abstract}

Palavras-chave: Nanocompósito; Poliuretano; Tecido ósseo.

\begin{abstract}
Nanocomposites with polyurethane matrix are materials with interesting properties for tissue engineering and can be used in the manufacture of scaffolds for bone regeneration. The objective of this research was to evaluate the evolution of scientific publications related to polyurethane matrix nanocomposites applied to bone tissue regeneration. Searches were conducted in the databases of Web of Science and Scopus, using a combination of keywords, and the results were tabulated and analyzed. The first documents date from 2009. China holds the largest number of publications, followed by Malaysia and Vietnam. The main research areas are Engineering, Materials Science and
\end{abstract}


Chemical Engineering. An increasing appreciation of the theme was noticed, with an increase in the production and impact of these publications. It can be considered that the question raised has great relevance because it is a promising field of study that promises to bring important advances to bone tissue engineering.

Keywords: Nanocomposite; Polyurethane; Bone tissue.

\section{Resumen}

Los nanocompuestos con matriz de poliuretano son materiales con interesantes propiedades para la ingeniería de tejidos y pueden utilizarse en la fabricación de andamios para la regeneración ósea. El objetivo de esta investigación fue evaluar la evolución de las publicaciones científicas relacionadas con los nanocompuestos de matriz de poliuretano aplicados a la regeneración de tejido óseo. Las búsquedas se realizaron en las bases de datos de las revistas Web of Science y Scopus, utilizando una combinación de palabras clave, y los resultados reportados fueron tabulados y analizados. Los primeros documentos se encontraron hasta la fecha de 2009. China tiene el mayor número de publicaciones, seguida de Malasia y Vietnam. Las principales áreas de investigación son la Ingeniería, la Ciencia de los Materiales y la Ingeniería Química. Hubo una creciente apreciación del tema, con un aumento en la producción y el impacto de estas publicaciones. Se puede considerar que la cuestión planteada tiene gran relevancia porque es un campo de estudio prometedor que promete aportar importantes avances a la ingeniería de tejidos óseos.

Palabras clave: Nanocompuesto; Poliuretano; Tejido óseo.

\section{Introdução}

Polímeros biodegradáveis são sintetizados a partir de óleos vegetais e se degradam sob condições favoráveis, podendo se decompor em semanas ou meses os quais são fabricados para serem utilizados como arcabouço para aplicação na engenharia de tecidos, e dentre esses polímeros, destaca-se o poliuretano (Filho, Luna, Siqueira, Araújo, \& Wellen, 2020; Jaganathan, Mani, Ayyar, \& Rathanasamy, 2019). Os poliuretanos (PU’s) são uma classe de materiais poliméricos com inúmeras propriedades e aplicações (Javaid et al., 2020). A síntese de poliuretano ocorre pela reação de poli adição entre polióis e diisocianatos na existência de um catalisador ou por iniciação por luz ultravioleta, resultando na formação de ligações uretano (-COONH-) com repetidas unidades (Carmo, Silva, \& Morelli, 2020; Gajbhiye, Chaudhari, Pokharkar, Pawar, \& Gajbhiye, 2020; Javaid et al., 2020). As propriedades do PU dependem do tipo de poliol e isocianato usados na síntese.

Como os polióis utilizados pelas indústrias são à base de petróleo, faz necessário a utilização de recursos renováveis e degradáveis como o óleo vegetal, o amido, quitosana, etc. (Dai et al., 2020). O óleo vegetal vem sendo bastante estudado devido aos triglicerídeos presentes na sua composição, possui uma estrutura molecular de carbono-carbono e ligação dupla que pode ser funcionalizada em polióis, usados na preparação de PU (Dai et al., 2020).

Para se obter diferentes tipos de PU, basta fazer combinações das matérias-primas como polióis, isocianatos e aditivos, com base em alguns estudos literários é possível observar alguns polióis biodegradáveis para a formação do PU (Thangavelu et al., 2020).

Os domínios moles e duros produzem uma separação por fase, que permite que esses materiais poliméricos resistam a tensões, propriedades tais como cristalinidade e dureza dependem da extensão de separação das fases (Francolini, Silvestro, Lisio, Martinelli, \& Piozzi, 2019; Javaid et al., 2020; Lowinger, Barrett, Zhang, \& Williams III, 2018).

Uma forte atração mútua ocorre no segmento duro por causa das ligações de hidrogênio, levando à criação de domínios entre os dois segmentos. Os domínios rígidos comportam-se como reticulações físicas termo-reversíveis e proporcionam as características termoplásticas e elastoméricas (Kim, Kang, Knowles, \& Gong, 2014). O grau de reticulação determina a tenacidade ou rigidez, um baixo grau de reticulação e cadeia longa resultam em um polímero muito flexível, em contrapartida, cadeias curtas com múltiplas reticulações formam um polímero rígido (Gajbhiye et al., 2020). O arranjo reticular de poliuretanos indica uma rede tridimensional com alto peso molecular (Gajbhiye et al., 2020). As propriedades a baixa temperatura são controladas pelo segmento mole e cristaliza apenas com um baixo nível do segmento duro ou por resfriamento (Kim et al., 2014). No entanto, os dois segmentos rígidos e flexíveis são termodinamicamente incompatíveis. Dessa forma, 
para induzir a separação por fase, os extensores decadeia são aplicados, sendo usualmente dióis ou bisaminas de baixo peso molecular (Lowinger et al., 2018).

A engenharia de tecidos vem ao longo do tempo procurando maneiras de promover a regeneração do tecido ósseo, pois é um problema clinico bastante comum (Ouyang, Cao, Dai, \& Qiu, 2021). Osteopromocação é uma barreira na qual impede a migração de células não osteogênicas para que promova a formação óssea (Saska et al., 2018). Enquanto a osteocondução são materiais que fornecem um ambiente favorável na qual ocorra o crescimento ósseo (Marmor, Matz, McClellan, Medam, \& Miclau, 2021). A osteoindução são materiais que possuem propriedades bioativas, ou seja, elas induzem a diferenciação de células-tronco mesenquimais em osteoblastos, que são células responsáveis na produção óssea e temos a osteogênese que são materiais que trazem células ósseas vivas do seu interior, que agem como um autoenxerto, fazendo com o que ocorra a formação do osso (Marmor et al., 2021).

Os PU's possuem diversas aplicações como em membrana de separação de gases, revestimentos de superfície, materiais de engenharia de tecidos e na área biomédica (Salgado et al., 2020). Na área biomédica e engenharia de tecidos os poliuretanos biodegradáveis são aplicados na fabricação de arcabouço na regeneração óssea, devido a sua hemocompatibilidade, biocompatibilidade, degradabilidade e não toxicidade e devido ás várias limitações, deficiências e complicações nos procedimentos clínicos atuais relatados para transplantes autólogos e alogênicos, ocorrendo uma diminuição no fornecimento de enxertos, infecção e morbidade do doador local, cicatriz e complicações cirúrgicas como, dor crônica e sangramento (Bharadwaz \& Jayasuriya, 2020; Gajbhiye et al., 2020; Jaganathan et al., 2019; Uscátegui et al., 2019).

Além da aplicação como arcabouço ortopédicos, os PU's são utilizados também como revestimento no tecido mole para regeneração, próteses vasculares e regeneração de nervos, isso devido as suas propriedades mecânicas e de superfície, resistência hidrolítica a enzimas bacterianas, baixa citoxicidade e boa hemocompatibilidade (Król, Uram, Król, Pielichowska, \& Walczak, 2018). É correto afirmar que avanços em tratamentos dessa natureaza são muito preciosos para a ciência, e certamente aumentam a capacidade da engenharia de tecidos e biomedicina de tratarem diferentes tipos de traumas com maior eficácia, e melhores resultados. É provavel que com a incorporação da vertente nanotecnológica à terapêutica do reparo ósseo, associado ao uso de polímeros altamente versáteis, como é o caso dos PU's, grandes serão os avanços para o tratamento e recuperação de pacientes com lesões sérias.

Os PU's do tipo arcabouço são bastante utilizados na engenharia de tecidos, na forma de nanocompósitos, a partir da incorporação de hidroxiapatita de cálcio na sua matriz polimérica que lhe confere propriedades bioativas e regeneração do tecido ósseo (Singh et al., 2020). Na síntese de nanocompósitos, nanomateriais são incorporadas em uma matriz, seja ela polimérica, cerâmica ou metálica, para melhorar suas propriedades, sendo elas, resistência, dureza, estabilidade térmica e leveza, os nanomateriais incorporados podem ser nanopartículas orgânicas, inorgânicas e poliméricas (hidroxiapatita, argila, grafeno e nanopartículas metálicas) (Akhan, Oktay, Özdemir, Madakbaş, \& Apohan, 2020; Asadi et al., 2017).

O elastômero de PU possui alta elasticidade sob uma determinada carga e após a remoção de uma força aplicada sua forma original é restaurada, dessa forma se torna adequado para o desenvolvimento de membranas regenerativas ósseas, atribuídas às suas propriedades viscoelásticas, propriedades mecânicas e diversidade química (Xie, Ouyang, Wang, \& Zhou, 2020). Suportes de PU impressos em 3D com biodegradabilidade, propriedades de memória de forma e osteogênese podem ser usados para procedimentos cirúrgicos minimamente invasivos em engenharia de tecido ósseo (Xie et al., 2020). Essa tecnologia da impressão em 3D esta sendo bastante utilizada para aplicação de renegeração do tecido ósseo, pois pode ser fabricado um material poroso que pode ser usado como um substituto ósseo, podendo ser adequado ao tipo de paciente e projetado por computador através das imagens de ressonância magnética e tomografia e reduz a incompatibilidade do material enxertado com o tecido nativo (Lee et al., 2019).

Observa-se que a maioria dos estudos em desenvolvimento estão em estágios iniciais, com testagens in vitro. As caracterizações das amostras, bem como os testes biológicos têm mostrado resultados positivos, denotando potencial 
aplicabilidade de nanocompósitos poliméricos à engenharia de tecido ósseo. Acredita-se, portanto, que com o crescimento da demanda, cada vez mais acentuada, por técnicas terapêuticas aplicadas ao reparo de tecidos ósseos ao redor do mundo (Bharadwaz \& Jayasuriya, 2020), pesquisas dessa natureza são muito aguardadas e notoriamente contribuição no tratamento desse tipo de enfermidade e para o avanço da ciência, em especial para a biomedicina, biotecnologia e engenharia de tecidos.

Para traçar um panorama da produção científica sobre a temática, muitos estudos de revisão bibliográfica são desenvolvidos, com base em critérios sistemáticos. A bibliometria nada mais é que uma técnica na qual são feitas medidas quantitativas dos índices tanto de produção escrita, como de difusão do conhecimento científico, tendo como indicadores de medidas do impacto cientifico, para que seja informado aos pesquisadores seu desempenho em uma área específica de conhecimento (Castro-Silva et al., 2021; Castro-Silva, Ferreira, \& Maciel, 2021). Nesse sentido, por meio de uma investigação minuciosa, baseada em documentos científicos, buscou-se compreender o panorama atual da produção científica com foco na utilização de nanocompósitos de poliuretano com aplicações para engenharia de tecido ósseo, na medida que muitos são os estudos realizados para aplicações de regeneração óssea, área muito cara às ciências biomédicas, de fundamental importância, tendo em vista os grandes desafios associados ao tratamento deste tecido, que por sua alta especificidade e complexidade, carece de soluções terapêuticas pontuais e eficazes cujo desenvolvimento, apesar de crescente, ainda é limitado.

Portanto, o presente trabalho teve como principal objetivo verificar a evolução das competências cientificas, bem como o panorama de publicações de artigos relacionados a nanocompósitos com matriz de poliuretano aplicados à regeneração do tecido ósseo, agrupando e classificando a produção científica de modo que se possa estabelecer uma melhor compreensão do tema.

\section{Metodologia}

Pode-se considerar, conforme (Gil, 2002) que o presente estudo caracteriza-se como uma pesquisa exploratória e descritiva, por alinhar o aprimoramento de ideias sobre um tema através de um levantamento bibliográfico, com a descrição das características pertinentes ao tópico em estudo, estabelecendo, então, uma relação entre as suas variáveis, e, quanto ao método, pode-se classificar como quantitativa, na medida que são coletados dados numéricos, os quais passam por análises matemáticas (Pereira, Shitsuka, Parreira, \& Shitsuka, 2018). Foi, portanto, realizada uma prospecção científica a partir do levantamento de artigos científicos publicados, referentes à utilização de nanocompósitos com matriz de poliuretano aplicados ao reparo ósseo. Para tanto, foi realizada inicialmente uma análise exploratória e, por conseguinte, seguiu-se com uma pesquisa documental, de natureza quantitativa, nas bases de dados Web of Science e Scopus. O levantamento dos dados foi realizado em setembro de 2020 com a utilização da seguinte combinação de palavras-chave: polyurethane and bone and tissue and engineering and nanocomposite, nos campos de título e/ou resumo. Para a análise dos dados foi utilizado o programa Microsoft Excel versão 2016. A Figura 1 ilustra o diagrama que associa os termos da busca com as bases de dados consultadas. 
Figura 1. Diagrama de palavras-chave e as bases de dados consultadas.

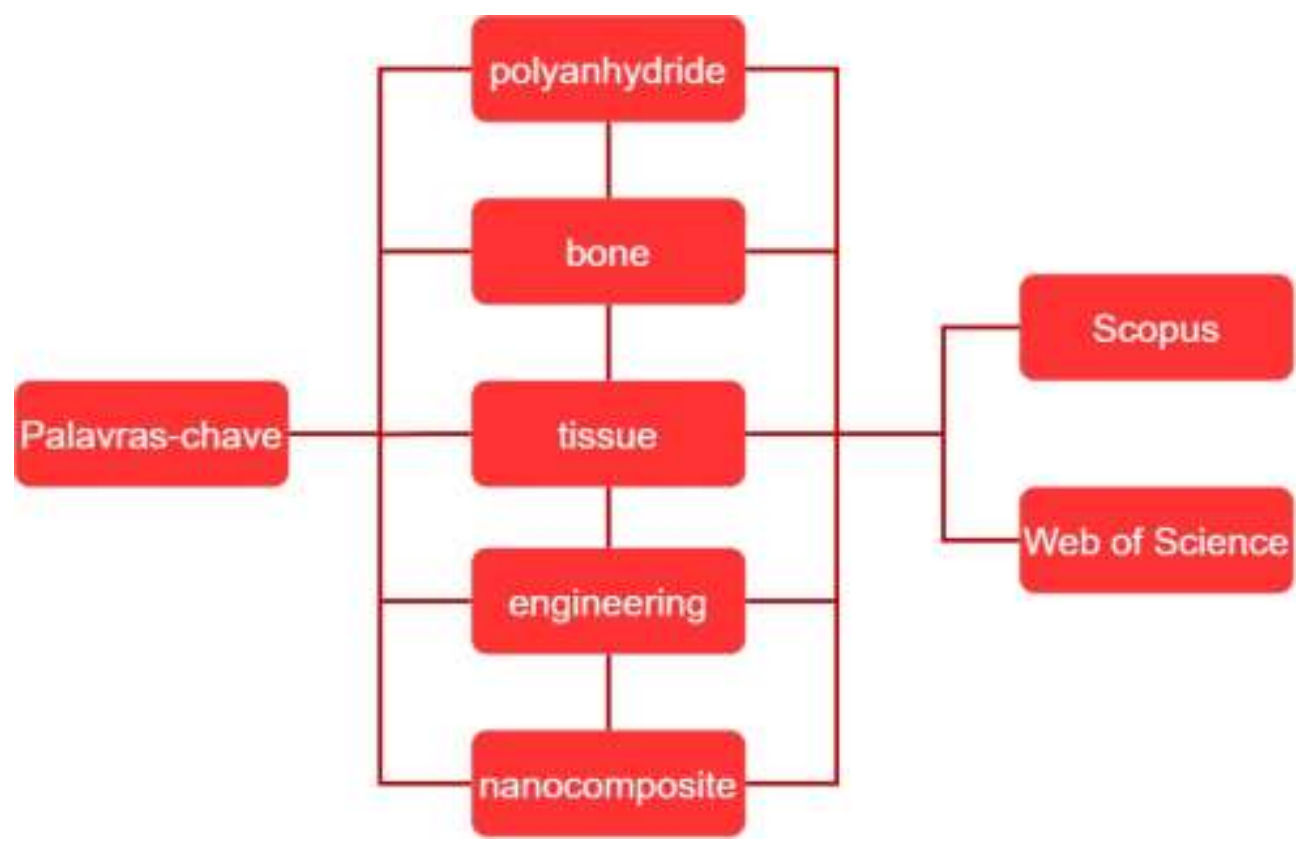

Fonte: Autores (2020).

\section{Resultados e Discussão}

Ao realizar as buscas nas bases de periódicos citadas, podemos observar que o termo "polyurethane", utilizado nas pesquisas isoladamente, obteve um número alto de resultados em ambas as bases: Scopus (70.454) e Web of Science (53.329), e à medida que são incluídos novos termos na truncagem, os resultados passam por um refinamento até se alcançar a combinação que melhor expressa o sentido da busca (Tabela 1).

Tabela 1. Relação entre o número de artigos encontrados nas bases de artigos utilizados e as palavras-chave.

\begin{tabular}{lcc}
\hline \multicolumn{1}{c}{ Palavras-chave } & Scopus & Web of Science \\
\hline Polyurethane & 70.454 & 53.329 \\
polyurethane and bone & 1.705 & 1.406 \\
polyurethane and bone and tissue & 748 & 659 \\
polyurethane and bone and tissue and engineering & 365 & 402 \\
polyurethane and bone and tissue and engineering and nanocomposite & 42 & 38 \\
\hline
\end{tabular}

Fonte: Autores (2020).

O poliuretano é um polímero que vem sendo bastante utilizado devido as suas diversas propriedades, adequando-se a várias aplicações, sendo, portanto, um material promissor, com vasto campo de aplicações. Quando é feito o refinamento das palavras-chave, pode-se observar que os números caem bastante, pois é redirecionado a uma aplicação específica, como no caso dos termos "polyurethane and bone and tissue and engineering and nanocomposite", restringindo os resultados reportados pelas bases e retornando menos documentos, em função da maior especificidade dos termos da busca.

Ao analisar os números referentes às publicações anualmente baseadas nos termos "polyurethane and bone and tissue and engineering and nanocomposite", observa-se que os primeiros documentos foram publicados em 2009, e nos anos seguintes observou-se que a produção seguiu sem grandes mudanças até 2016, não ultrapassando 3 registros por ano. Contudo, a produção dos anos seguintes teve um aumento considerável, com maior número de registros em 2019, 13 publicações, e em 2020, até o momento da pesquisa, foram publicados 6 artigos, como podemos ver na Figura 2. 
Figura 2. Número de documentos publicados ao longo dos anos.

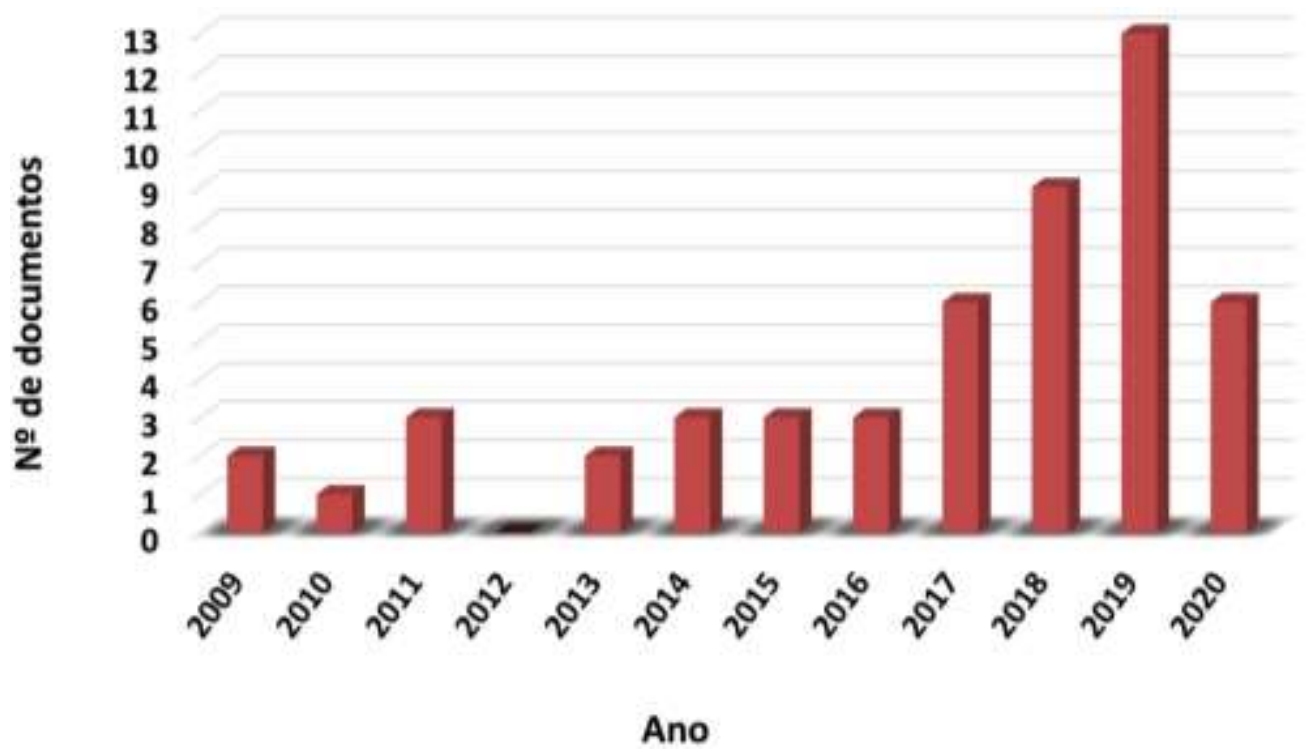

Fonte: Autores (2020).

A base industrial para os poliuretanos que evoluiu nos últimos 50 anos foi impulsionada basicamente por dois fatores, o primeiro sendo a economia da produção da matéria-prima e o segundo a diversidade do mercado de plásticos duros e tintas adesivas. Atualmente, os PU's detêm uma das maiores participações de mercado na indústria de plásticos e CASE (revestimentos, adesivos, selantes e elastômeros), e, por suas propriedades superiores, assumiram vários tipos de aplicações, inclusive aplicações biomédicas (Das \& Mahanwar, 2020). Pode-se associar o vultuoso ganho na produção de PU's ao crescente avanço nos estudos sobre as aplicações do material. Acredita-se, portanto, que com tecnologias emergentes será possível desenvolver melhores estudos sobre traumatologia, bem como o surgimento de inovações no tratamento do trauma ósseo (Zhao, Guan, Liu, Tian, \& Li, 2020).

Um dos artigos publicados em 2009 intitulada como "Nanohydroxyapatite/poly(ester urethane) scaffold for bone tissue engineering”, relata a preparação de arcabouços compostos de nanopartículas de hidroxiapatita (nHA)/poli (éster uretano) viscoelástico biodegradável para aplicação como construtos osteocondutores para a engenharia de tecido ósseo (Boissard, Bourban, Tami, Alini, \& Eglin, 2009). Em 2020, foi publicado o trabalho intitulado "Fabrication of calcium hydroxyapatite incorporated polyurethane-graphene oxide nanocomposite porous scaffolds from poly (ethylene terephthalate) waste: A green route toward bone tissue engineering”, o qual aborda a preparação de arcabouços polimérico poroso e biodegradável a partir de poliuretano com a finalidade de regenerar células de osteoblastos para utilizar na restauração de tecidos ósseos danificados (Singh et al., 2020).

Na Figura 3 observa-se o gráfico referente ao número de documentos publicados por país, e nota-se que a Chia é o país que lideram o ranking com 15 publicações, logo em seguida tem a Malásia e o Vietnã com 10 publicações cada, e, em $14^{\circ}$ lugar, temos o Brasil, com apenas uma publicação. Isso mostra que a pesquisa nessa área ainda é muito incipiente para alguns países, enquanto outros parecem estar mais familiarizados ao tema, e por isso apresentam maior produção. Não obstante, também é importante ressaltar que essa área vem despertando interesse entre os pesquisadores, e alguns países tem se dedicado ao estudo dessas aplicações. Os Estados Unidos vêm apresentando recente interesse pelo tema nos últimos anos, notando-se um estímulo crescente para o desenvolvimento de pesquisa nessa área, evidenciando o seu caráter promissor e relevância para a comunidade acadêmica e para a indústria. 
Figura 3. Relação de países com o número de publicações de documentos.

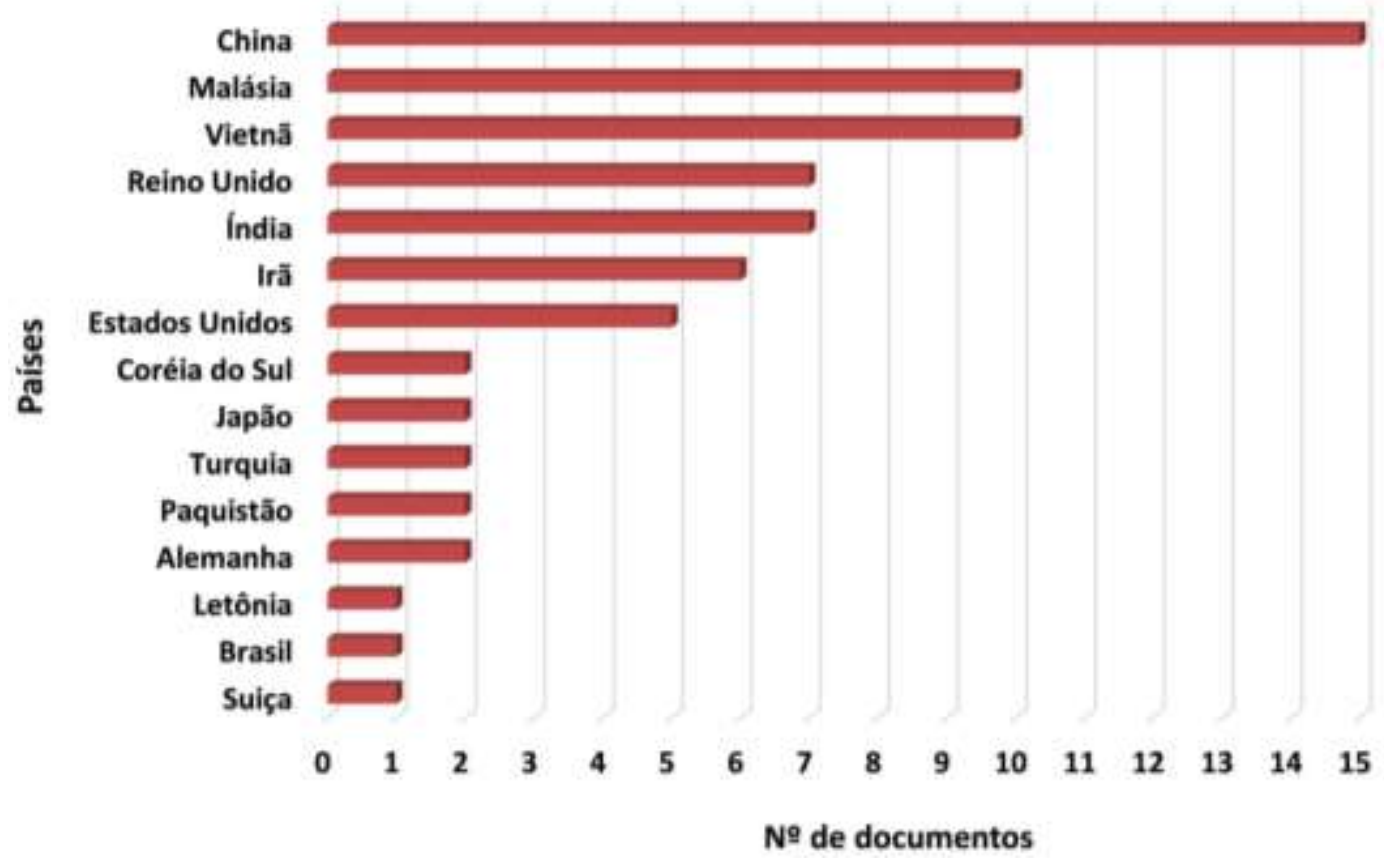

Fonte: Autores (2020).

$\mathrm{Na}$ Figura 4 podemos visualizar as áreas que tiveram publicações referente aos termos "polyurethane and bone and tissue and engineering and nanocomposite". Dentre as áreas destacadas, podemos citar Ciência dos materiais (19\%), Engenharia (18\%), Engenharia química (12\%) e a Química (12\%), como sendo as áreas que apresentam maior destaque, e, consequentemente, maior número de publicações sobre a temática. Semelhantemente, também é possível observar que além das engenharias, química e ciência dos materiais, outras áreas também estão começando a se interessar pelo tema, como farmacologia, agricultura e ciências biológicas, medicina, bioquímica, genética e biologia molecular, dentre outras, evidenciando, desta forma, o caráter multidisciplinar e a polivalência relacionada aos nanocompósitos com matriz de poliuretano visando aplicações para o reparo do tecido ósseo nas suas mais variadas vertentes.

Figura 4. Relação entre as áreas com o número de publicações de documentos.
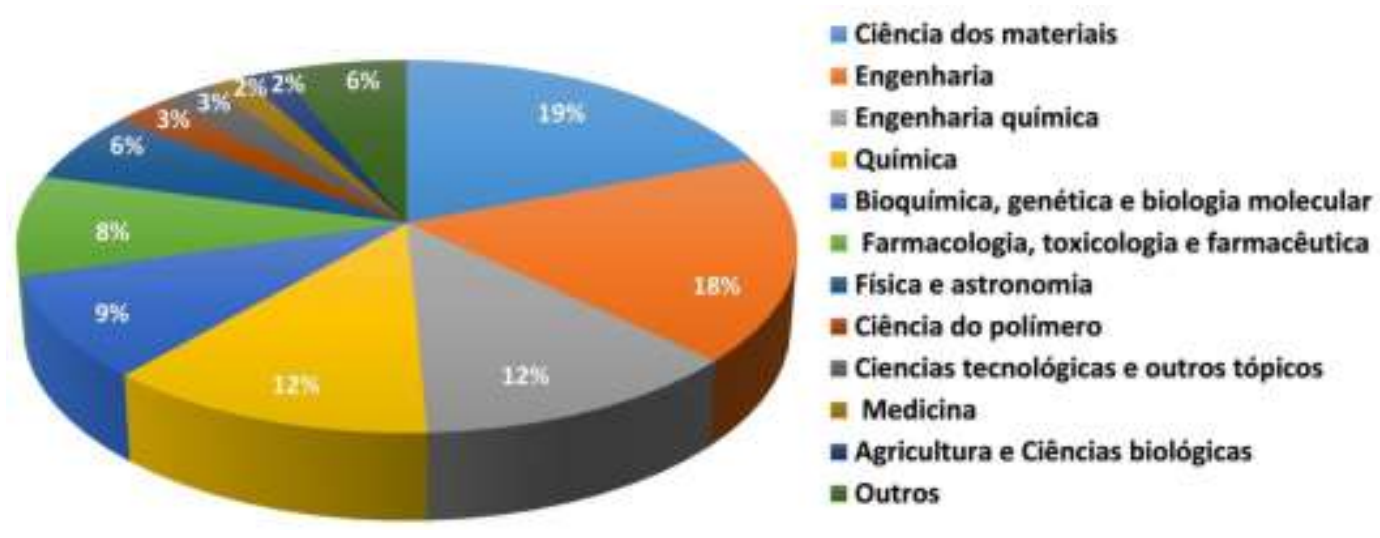

Fonte: Autores (2020).

Portanto, fica clara a amplitude e o dinamismo sobre aplicação de PU's no campo da engenharia de tecidos, proposta nesse estudo, sendo capaz de dialogar entre diferentes áreas pelo seu caráter multidisciplinar, sendo necessária a cooperação entre diferentes especialistas em áreas como medicina, biologia, biotecnologia e ciências dos materiais para o desenvolvimento 
de novas tecnologias e potenciais aplicações, as quais ficarão a cargo dos biólogos entender os mecanismos que ocorrem entre o biomaterial e o hospedeiro (Marzec, Kucińska-Lipka, Kalaszczyńska, \& Janik, 2017).

Ao analisarmos os tipos de publicações (Figura 5), podemos observar que o número de artigos originais é bem superior aos demais tipos de documentos, possuindo $84 \%$ do total de publicações, mostrando que há um grande interesse dos pesquisadores por novas contribuições cientificas. Em adição, também se observa que artigos de conferência (8\%), artigos de revisão (6\%) e anais de eventos (2\%) também estão entre os tipos de trabalhos publicados sobre a temática, demonstrando que essas contribuições, apesar de em menor proporção em termos de produção, também são modais escolhidos pelos pesquisadores para apresentar os resultados de suas pesquisas, colaborando para maior divulgação desses estudos entre a comunidade científica.

Figura 5. Relação entre os tipos de documentos com o número de publicações.

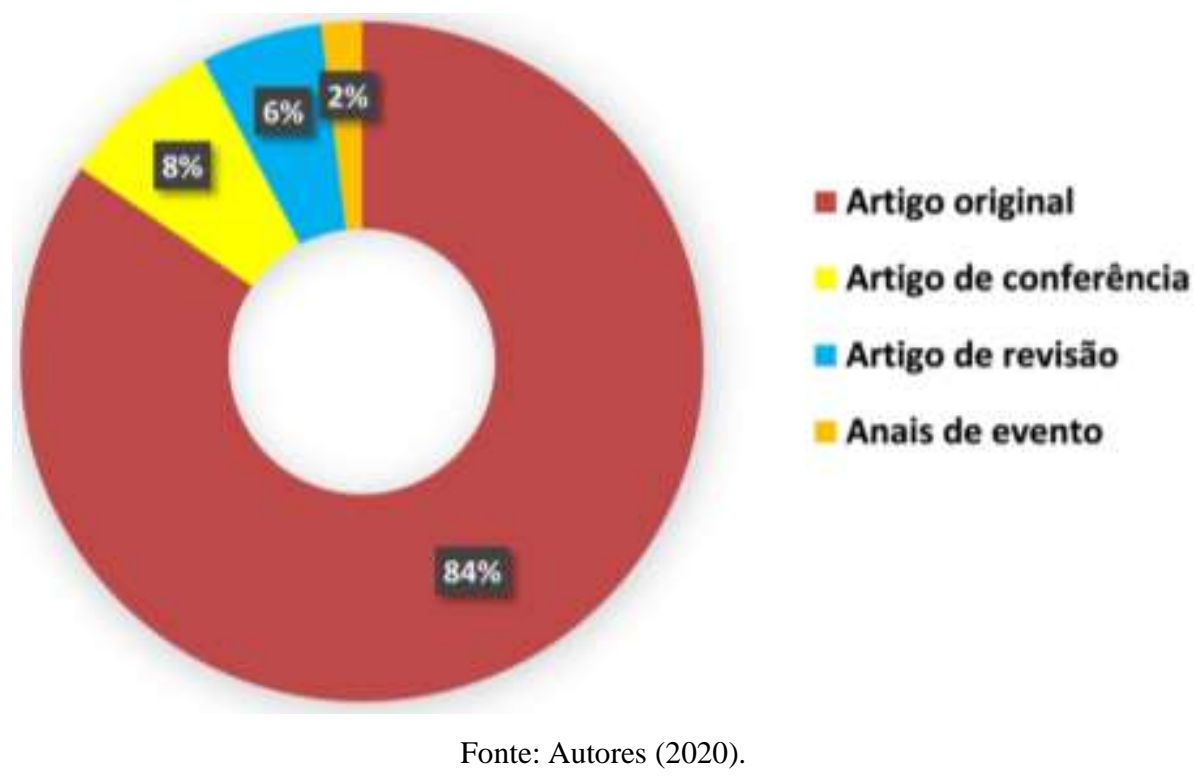

Na Figura 6 é ilustrado um gráfico no qual observa-se as citações feitas por ano aos artigos científicos publicados sobre a temática proposta, destacando, deste modo, o impacto desses artigos. Podemos observar que a curva apresenta um crescimento quase que linear e constante. O número de vezes que esses documentos vêm sendo citados por outros trabalhos está aumentando a cada ano, deixando em evidência a produção crescente e impacto dessas produções. Em 2009 não houve nenhuma citação, pois foi quando foram publicados os primeiros artigos sobre o assunto. Contudo, nota-se que em 2020 até o momento da pesquisa, foram contabilizadas 140 citações, evidenciando a notoriedade e o impacto da produção científica nessa área. 
Figura 6. Relação do número de citações por ano.

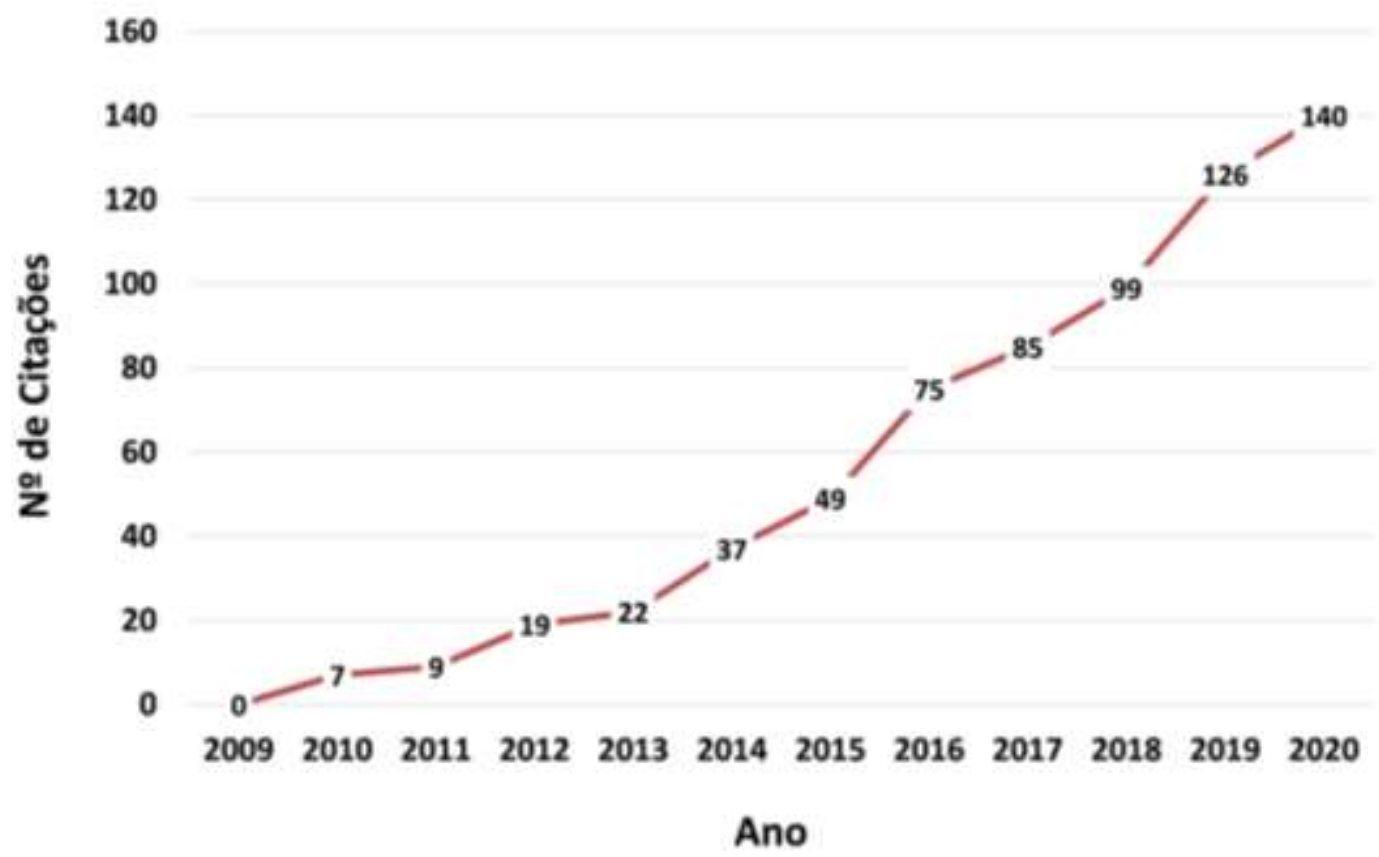

Fonte: Autores (2020).

Entre os artigos reportados pelas bases de dados, destaca-se Nano-Hydroxyapatite Composite Biomaterials for Bone Tissue Engineering-A Review, de autoria de (Venkatesan \& Kim, 2014), o qual é uma revisão que apresenta um apanhado sobre o desenvolvimento de substitutos ósseos a partir de nanobiocompósitos, necessariamente nanocompósitos baseados na biocerâmica hidroxiapatita associada a outros materiais, dentre eles o poliuretano, bem como avalia também os métodos de preparação, interação química biocompatibilidade, biodegradação, dentre outras propriedades. Por outro lado, destaca-se a referida publicação pelo seu alto impacto, evidenciado pelo elevado número de vezes que foi citado, sendo o documento com maior número de citações entre os reportados pelas bases para o chaveamento considerado, de modo que o mesmo apresentou um total de 164 citações na Web of Science, o que significa que este artigo foi citado por outros 164 trabalhos nessa base, e, na Scopus, o artigo contou um total de 179 citações, reforçando, assim, o quão impactante foi essa pesquisa para a área, e semelhante a ela, existem também outras de alto impacto, reforçando o caráter promissor da área.

\section{Considerações Finais}

Verifica-se, portanto, que o desenvolvimento de pesquisas referentes ao tema proposto, figurado pela busca nas bases especializadas a partir da combinação de palavras-chave "polyurethane and bone and tissue and engineering and nanocomposite" é crescente, porém ainda muito incipiente e pouco explorado, mas de grande potencial e vasto campo de aplicação, como se observou pelo alto impacto das publicações da área, mesmo no curto espaço de tempo observado entre as primeiras e as últimas publicações identificadas por essa pesquisa, de modo que se faz necessário maior incentivo entre os pesquisadores, seja por iniciativa pública ou privada, no sentido de possibilitar maiores avanços no desenvolvimento dessa tecnologia, seja para o desenvolvimento de PU para a aplicações em regeneração do tecido ósseo, como também, tendo em vista o seu caráter promissor para outras aplicações tecnológicas.

Em adição, a título de sugestão para trabalhos futuros, propõe-se uma investigação científica e tecnológica, nesse sentido, alinhando documentos patentários aos artigos científicos, para o mapeamento de novas tecnologias que empregam a utilização de nanocompósitos de poliuretano aplicados ao reparo do tecido ósseo, com a intenção de entender como se dá o 
desenvolvimento de trabalhos dessa natureza, como também identificar novas tecnologias desenvolvidas para esta finalidade, descrevendo-as e percebendo quais os rumos essa potencial área tecnológica irá tomar.

\section{Referências}

Akhan, S., Oktay, B., Özdemir, O. K., Madakbaş, S., \& Apohan, N. K. (2020). Polyurethane graphene nanocomposites with self-healing properties by azidealkyne click reaction. Materials Chemistry and Physics, 254, 123315. https://doi.org/10.1016/j.matchemphys.2020.123315

Asadi, N., Alizadeh, E., Salehi, R., Khalandi, B., Davaran, S., \& Akbarzadeh, A. (2017). Nanocomposite hydrogels for cartilage tissue engineering: a review. Artificial Cells, Nanomedicine and Biotechnology, 46(3), 465-471. https://doi.org/10.1080/21691401.2017.1345924

Bharadwaz, A., \& Jayasuriya, A. C. (2020). Recent trends in the application of widely used natural and synthetic polymer nanocomposites in bone tissue regeneration. Materials Science and Engineering C, 110(January), 110698. https://doi.org/10.1016/j.msec.2020.110698

Boissard, C. I. R., Bourban, P.-E., Tami, A. E., Alini, M., \& Eglin, D. (2009). Nanohydroxyapatite/poly(ester urethane) scaffold for bone tissue engineering. Acta Biomaterialia, 5(9), 3316-3327. http://dx.doi.org/10.1016/j.actbio.2009.05.001

Carmo, K. M. do, Silva, M. C. da, \& Morelli, C. L. (2020). Reaproveitamento de resíduo de espuma rígida de poliuretano em uma matriz termoplástica de poliuretano. Research, Society and Development, 9(3), e127932695. http://dx.doi.org/10.33448/rsd-v9i3.2695

Castro-Silva, I. I., Araújo, L. K., Souza, F. F. P. de, Ponte, J. S., Sousa, E. M. de, Jiménez, H. G. Q., Ferreira, F. V., et al. (2021). Pesquisa odontológica brasileira em regeneração óssea guiada: um estudo bibliométrico de quatro décadas Brazilian dental research in guided bone regeneration : a bibliometric study of four decades Investigación dental brasileña em regeneración ósea guiad. Research, Society and Development, 10(2), e25510212504. http://dx.doi.org/10.33448/rsd-v10i2.12504

Castro-Silva, I. I., Ferreira, F. V., \& Maciel, J. A. C. (2021). Pesquisas em Biotecnologia no Brasil: Uma correlação espacial entre índice-H e desenvolvimento social. Research, Society and Development, 10(1), e29910111807. http://dx.doi.org/10.33448/rsd-v10i1.11807

Dai, Z., Jiang, P., Lou, W., Zhang, P., Bao, Y., Gao, X., Xia, J., et al. (2020). Preparation of degradable vegetable oil-based waterborne polyurethane with tunable mechanical and thermal properties. European Polymer Journal, 139(September), 109994. https://doi.org/10.1016/j.eurpolymj.2020.109994

Das, A., \& Mahanwar, P. (2020). A brief discussion on advances in polyurethane applications. Advanced Industrial and Engineering Polymer Research, 3(3), 93-101. https://doi.org/10.1016/j.aiepr.2020.07.002

Filho, E. A. dos S., Luna, C. B. B., Siqueira, D. D., Araújo, E. M., \& Wellen, R. M. R. (2020). Efeito do recozimento nas propriedades mecânicas, térmicas e termomecânicas da PCL. Research, Society and Development, 9(12), e13191210764. http://dx.doi.org/10.33448/rsd-v9i12.10764

Francolini, I., Silvestro, I., Lisio, V. Di, Martinelli, A., \& Piozzi, A. (2019). Synthesis, characterization, and bacterial fouling-resistance properties of polyethylene glycol-grafted polyurethane elastomers. International Journal of Molecular Sciences, 20(4). https://doi:10.3390/ijms20041001

Gajbhiye, K. R., Chaudhari, B. P., Pokharkar, V. B., Pawar, A., \& Gajbhiye, V. (2020). Stimuli-responsive biodegradable polyurethane nano-constructs as a potential triggered drug delivery vehicle for cancer therapy. International Journal of Pharmaceutics, 588(July), 119781. https://doi.org/10.1016/j.ijpharm.2020.119781

Gil, A. C. (2002). Como elaborar projetos de pesquisa. ATLAS, 93(3), 529-536.

Jaganathan, S. K., Mani, P. M., Ayyar, M., \& Rathanasamy, R. (2019). Biomimetic electrospun polyurethane matrix composites with tailor made properties for bone tissue engineering scaffolds. Polymer Testing, 78(June), 105955. https://doi.org/10.1016/j.polymertesting.2019.105955

Javaid, M. A., Zia, K. M., Iqbal, A., Ahmad, S., Akram, N., Liu, X., Nawaz, H., et al. (2020). Utilization of waxy corn starch as an efficient chain extender for the preparation of polyurethane elastomers. International Journal of Biological Macromolecules, 148, 415-423. https://doi.org/10.1016/j.ijbiomac.2020.01.011

Kim, H.-J., Kang, M.-S., Knowles, J. C., \& Gong, M.-S. (2014). Synthesis of highly elastic biocompatible polyurethanes based on bio-based isosorbide and poly(tetramethylene glycol) and their properties. Journal of Biomaterials Applications, 29(3), 454-464. https://doi.org/10.1177/0885328214533737

Król, P., Uram, Ł., Król, B., Pielichowska, K., \& Walczak, M. (2018). Study of chemical, physico-mechanical and biological properties of 4,4'methylenebis(cyclohexyl isocyanate)-based polyurethane films. Materials Science \& Engineering C, 93(August), 483-494. https://doi.org/10.1016/j.msec.2018.07.082

Lee, S. J., Won, J.-E., Han, C., Yin, X. Y., Kim, H. K., Nah, H., Kwon, I. K., et al. (2019). Development of a three-dimensionally printed scaffold grafted with bone forming peptide-1 for enhanced bone regeneration with in vitro and in vivo evaluations. Journal of Colloid and Interface Science, 539, 468-480. https://doi.org/10.1016/j.jcis.2018.12.097

Lowinger, M. B., Barrett, S. E., Zhang, F., \& Williams III, R. O. (2018). Sustained release drug delivery applications of polyurethanes. Pharmaceutics, 10(2), 1-19. https://doi:10.3390/pharmaceutics10020055

Marmor, M. T., Matz, J., McClellan, R. T., Medam, R., \& Miclau, T. (2021). Use of Osteobiologics for Fracture Management: The When, What, and How. Injury, (xxxx). https://doi.org/10.1016/j.injury.2021.01.030

Marzec, M., Kucińska-Lipka, J., Kalaszczyńska, I., \& Janik, H. (2017). Development of polyurethanes for bone repair. Materials Science and Engineering C, 80, 736-747. http://dx.doi.org/10.1016/j.msec.2017.07.047

Ouyang, L., Cao, J., Dai, Q., \& Qiu, D. (2021). New insight of immuno-engineering in osteoimmunomodulation for bone regeneration. Regenerative Therapy, 
Research, Society and Development, v. 10, n. 4, e31910414245, 2021

(CC BY 4.0) | ISSN 2525-3409 | DOI: http://dx.doi.org/10.33448/rsd-v10i4.14245

18, 24-29. https://doi.org/10.1016/j.reth.2021.03.003

Pereira, A. S., Shitsuka, D. M., Parreira, F. J., \& Shitsuka, R. (2018). Medologia da Pesquisa Científica. Metodologia da Pesquisa Científica.

Salgado, C., Arrieta, M. P., Sessini, V., Peponi, L., López, D., \& Fernández-García, M. (2020). Functional properties of photo-crosslinkable biodegradable polyurethane nanocomposites. Polymer Degradation and Stability, 178. https://doi.org/10.1016/j.polymdegradstab.2020.109204

Saska, S., Pigossi, S. C., Oliveira, G. J. P. L., Teixeira, L. N., Capela, M. V., Gonçalves, A., De Oliveira, P. T., et al. (2018). Biopolymer-based membranes associated with osteogenic growth peptide for guided bone regeneration. Biomedical Materials (Bristol), 13(3). https://doi.org/10.1088/1748-605X/aaaa2d

Singh, A., Banerjee, S. L., Dhiman, V., Bhadada, S. K., Sarkar, P., Khamrai, M., Kumari, K., et al. (2020). Fabrication of calcium hydroxyapatite incorporated polyurethane-graphene oxide nanocomposite porous scaffolds from poly (ethylene terephthalate) waste: A green route toward bone tissue engineering. Polymer, 195(November 2019), 122436. https://doi.org/10.1016/j.polymer.2020.122436

Thangavelu, S. A. G., Mukherjee, M., Layana, K., Dinesh Kumar, C., Sulthana, Y. R., Rohith Kumar, R., Ananthan, A., et al. (2020). Biodegradable polyurethanes foam and foam fullerenes nanocomposite strips by one-shot moulding: Physicochemical and mechanical properties. Materials Science in Semiconductor Processing, 112(February), 105018. https://doi.org/10.1016/j.mssp.2020.105018

Uscátegui, Y. L., Díaz, L. E., Gómez-Tejedor, J. A., Vallés-Lluch, A., Vilariño-Feltrer, G., Serrano, M. A., \& Valero, M. F. (2019). Candidate polyurethanes based on castor oil (ricinus communis), with polycaprolactone diol and chitosan additions, for use in biomedical applications. Molecules, 24(2). https://doi:10.3390/molecules24020237

Venkatesan, J., \& Kim, S. K. (2014). Nano-hydroxyapatite composite biomaterials for bone tissue engineering - A review. Journal of Biomedical Nanotechnology, 10(10), 3124-3140. https://doi:10.1166/jbn.2014.1893

Xie, W., Ouyang, R., Wang, H., \& Zhou, C. (2020). Construction and Biocompatibility of Three-Dimensional Composite Polyurethane Scaffolds in Liquid Crystal State. ACS Biomaterials Science and Engineering, 6(4), 2312-2322. https://dx.doi.org/10.1021/acsbiomaterials.9b01838

Zhao, W. J., Guan, J. J., Liu, G. E., Tian, Y., \& Li, L. (2020). Annual review of Chinese Journal of Traumatology 2019. Chinese Journal of Traumatology English Edition, 23(1), 1-4. https://doi.org/10.1016/j.cjtee.2020.01.001 